\title{
An acoustic emission slope displacement rate sensor - case studies
}

\author{
N Dixon Loughborough University, UK \\ D Codeglia Loughborough University, UK \\ A Smith Loughborough University, UK \\ G Fowmes Loughborough University, UK \\ P Meldrum British Geological Survey, UK
}

\begin{abstract}
Research over a period of 20 years has resulted in development of a battery operated unitary acoustic emission (AE) sensor which, when used with a standard active waveguide installation, can quantify soil slope displacement rates continuously and in near real-time. The active waveguide is installed in a borehole through existing or anticipated shear zones, and comprises a steel tube with granular soil surround. The $A E$ sensor is located at ground level and with the waveguide is encased in a cover. Deformation of the slope strains the granular backfill, which generates AE through rearrangement of the particles. The AE propagate as stress waves along the steel tube to the ground surface where they are detected and quantified by the sensor, which is used to provide alert text messages if pre-determined thresholds are exceeded. The use of a reproducible waveguide allows standard interpretation of the generated AE to provide information on soil slope displacement rates, and the granular soil backfill generates measureable AE when the system is installed in slopes formed in 'quiet' fine grained soils. The approach monitors AE at high frequencies to exclude environmental background noise and hence ensure that false alarms are not generated. In rock slopes, the grouted waveguide is passive, with measured AE generated by rock deformation mechanisms. The sensors have been deployed on multiple sites in the UK and in Italy, Austria and Canada. At all sites performance of the AE sensors has been compared with traditional deformation monitoring instrumentation including ShapeAccelArray, inclinometer, extensometer and time-domain reflectometry. Measurements from these field studies have demonstrated that generated AE are proportional to slope displacement rates. This paper outlines the AE measurement and the interpretation techniques developed, and presents field comparisons of measured $A E$ trends and slope displacement rates obtained from extended trials at several sites. It is concluded that the AE technique can be used as a reliable early warning system for soil slope instability. Applications in rock slopes are promising but further work is required to link detected AE to rock deformation mechanisms and hence to derive thresholds as a basis for early warnings.
\end{abstract}

\section{Introduction}

Landslides cause thousands of fatalities each year worldwide. Petley (2012) reported records of over 32,000 landslide-induced fatalities that occurred during the period 2004 to 2010, and damage built environment infrastructure costing billions of pounds to repair, resulting in thousands of people being made homeless and the breakdown of basic services such as water supply and transport. The cost of remediation subsequent to landslide failure is very high (often ten times greater) compared to the cost of corrective measures and repairs if conducted prior to collapse (Glendinning et al. 2009). This highlights the importance of slope stability monitoring. There is a clear need for affordable instrumentation that can provide continuous, remote, near real-time information with high temporal resolution on slope movements for use in the protection of people and infrastructure by practitioners.

Acoustic emissions ( $A E$ ) are high-frequency stress waves that propagate through materials surrounding the generation source. AE monitoring is widely used in many industries to detect and locate defects and leaks 
in pipe networks and pressure vessels, degradation of reinforced concrete due to straining and corrosion, breakages in wire ropes, and deterioration of rotating machines (e.g. bearings, engines, gearboxes and pumps). In soil, $A E$ is generated from inter-particle friction and in rock by fracture propagation and displacement along discontinuities. Hence, the detection of $A E$ is an indication of deformation.

In order to apply the AE monitoring approach to soil slopes, Dixon et al. (2003) conceived the active waveguide (Figure 1). This is installed in a borehole through existing or anticipated shear zones. Deformation of the slope strains the waveguide generating detectable AE. The use of a reproducible 'active' waveguide allows standard interpretations from the system to be developed. Additionally, the granular backfill soil generates measurable $A E$ and overcomes the small magnitude AE generated by slopes formed of 'quiet' fine-grained soils. AE monitoring using active waveguides has become an established approach to monitor the stability of soil slopes; however, the challenge has been to develop strategies to quantify deformation behaviour from the measured AE. Physical modelling (e.g. Dixon \& Spriggs 2007; Smith \& Dixon 2014) and field trials (e.g. Dixon et al. 2003; Dixon et al. 2014; Smith et al. 2014a; Dixon et al. 2015) have demonstrated that active waveguide-generated $A E$ is proportional to the rate of deformation, and this relationship can be quantified to allow slope displacement rates to be derived from measured AE.

Research over a period of 20 years has resulted in development of a battery operated unitary AE measurement sensor node, which when used with a standard active waveguide installation can quantify slope displacement rates continuously and in near real-time. The AE sensor node is located at ground level and with the waveguide is encased in a cover. Measured AE are detected by a transducer coupled to the waveguide and quantified by the sensor node, which is used to provide alert text messages if pre-determined thresholds are exceeded. The approach monitors $A E$ at high frequencies to exclude environmental background noise and hence ensure that false alarms are not generated. The sensors have been deployed on multiple sites in the UK and in Italy, Austria and Canada. At all sites performance of the $\mathrm{AE}$ system has been compared with traditional deformation monitoring instrumentation including ShapeAccelArray (SAA), conventional inclinometers, extensometers and time-domain reflectometry (TDR). This paper outlines the $A E$ measurement system and interpretation techniques developed, presents field comparisons of measured $A E$ trends and slope displacement rates obtained from extended trials at several sites, and considers use of the technique as an early warning system for slope instability. 


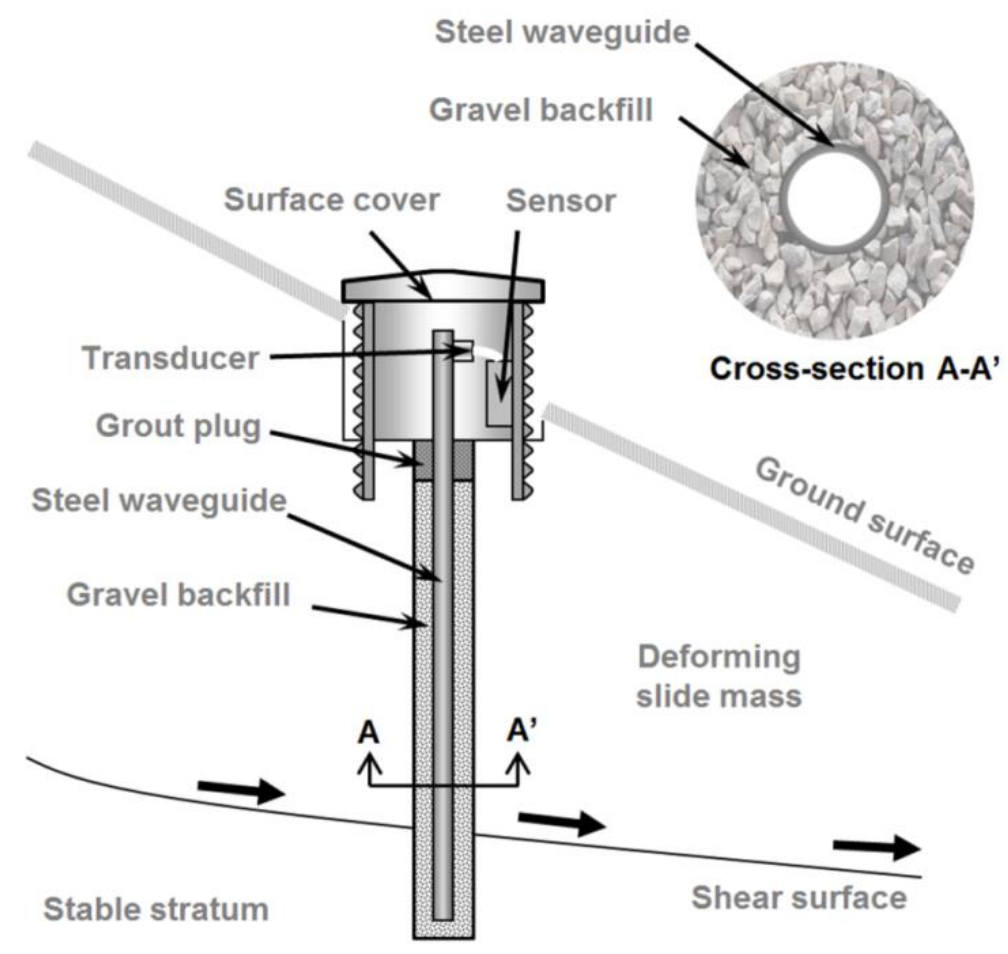

Figure 1 Schematic of an active waveguide installed through a soil slope deforming on a shear plane, with a sensor connected at the ground surface and protected by a cover (after Dixon et al. 2012a; Smith et al. 2014a)

\section{The acoustic emission monitoring approach}

The active waveguide (Figure 1) is installed in a borehole that penetrates stable stratum below any shear surface or potential shear surface that may form beneath a slope. It comprises a metal waveguide with a granular backfill soil surround. When the host slope deforms, the column of granular soil also deforms generating $A E$ that can propagate along the waveguide. A transducer coupled to the waveguide at the ground surface converts the $A E$ to an electrical signal, which is sequentially processed by the AE sensor. The $\mathrm{AE}$ sensor amplifies the signal and removes frequencies outside of the 20 to $30 \mathrm{kHz}$ range. This is an important step in removing low frequency $(<20 \mathrm{kHz})$ background noise such as traffic and construction activity. The sensor then logs the number of times the waveform crosses a pre-programmed voltage threshold level within pre-set time intervals; ring-down counts (RDC) per unit time (AE rates). The AE monitoring system that has been developed is called Slope ALARMS (Assessment of Landslides using Acoustic Real-time Monitoring Systems). Figure 2 shows an annotated photograph of the system taken from inside a surface cover. 


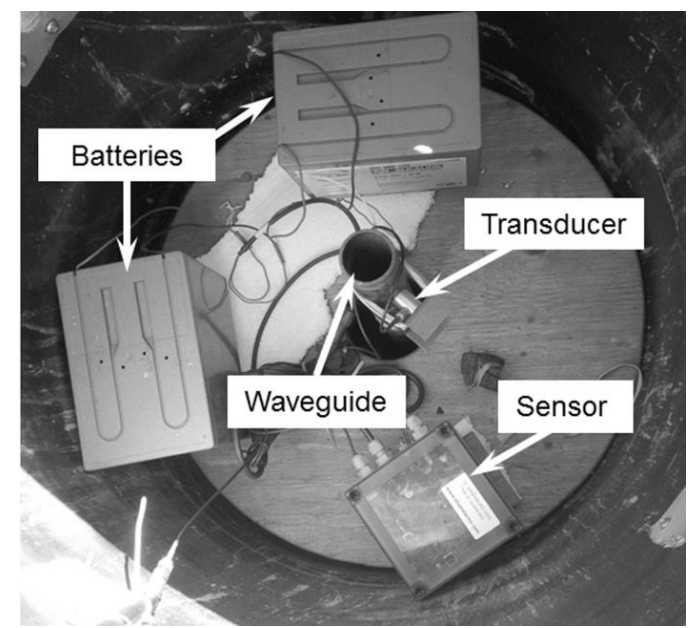

\section{Figure 2 Photograph of the Slope ALARMS AE measurement system from inside the protective surface cover (after Smith et al. 2014b)}

Dixon et al. (2014), Smith and Dixon (2014) and Smith et al. (2014a) introduced the coefficient of proportionality $\left(C_{p}\right)$ as a function that defines the empirical relationship between $A E$ rates generated from the system in response to an applied velocity of slope movement (Equations 1 and 2).

$$
\begin{gathered}
\text { AErate } \propto \text { velocity } \\
\text { AErate }=C_{p} \times \text { velocity }
\end{gathered}
$$

where:

$C_{p:} \quad=$ is a function of the variables.

An increasing rate of deformation (i.e. in response to increasing slope velocity) within the active waveguide generates an increasing number of particle-particle/particle-waveguide interactions. Each of these interactions generates a transient $A E$ event. These transient $A E$ events combine and propagate along the waveguide where they are monitored by the sensor at the ground surface. Hence, AE rates produced and measured by the system are proportional to the velocity of slope movement. The coefficient of proportionality is a measure of the systems sensitivity (i.e. the magnitude of $A E$ rates produced in response to an applied velocity) and is dependent on many variables related to the AE measurement system, such as the sensor sensitivity controlled by signal amplification and voltage threshold; the depth to the shear surface that influences the magnitude of $A E$ signal attenuation as it is transmitted from the shear zone to the ground surface by the waveguide; and active waveguide properties such as the tube geometry and backfill properties. The magnitude of $A E$ rate responses produced by each measurement system will depend on these factors, in addition to the rate of slope displacement (Smith et al. 2014a).

AE rates recorded by the measurement system in each monitoring interval are compared to a series of threshold levels, which are derived from the order of magnitude slope displacement rate classifications (e.g. Cruden \& Varnes 1996): 'slow' (e.g. $1 \mathrm{~mm} /$ hour), 'moderate' (e.g. $100 \mathrm{~mm} /$ hour) and 'rapid' (e.g. 10,000 mm/hour). If a Slope ALARMS sensor detects RDC within a set time period that exceeds a trigger warning level then the sensor transfers this to the communication system through a wireless network link. The communication system subsequently sends an SMS message to responsible persons so that relevant action can be taken (e.g. send an engineer to inspect the slope or immediately stop traffic). The absence of generated SMS messages means that slope displacement rates are lower than the minimum threshold set. Automatically generated daily health SMS messages provide information on the status of the system, demonstrating it is operational. The system therefore provides continuous near real-time information on slope displacement rates with high temporal resolution (i.e. monitoring periods are typically 15 or 30 minutes) (Dixon et al. 2015). Figure 3 shows an operation schematic of the AE early warning system. 


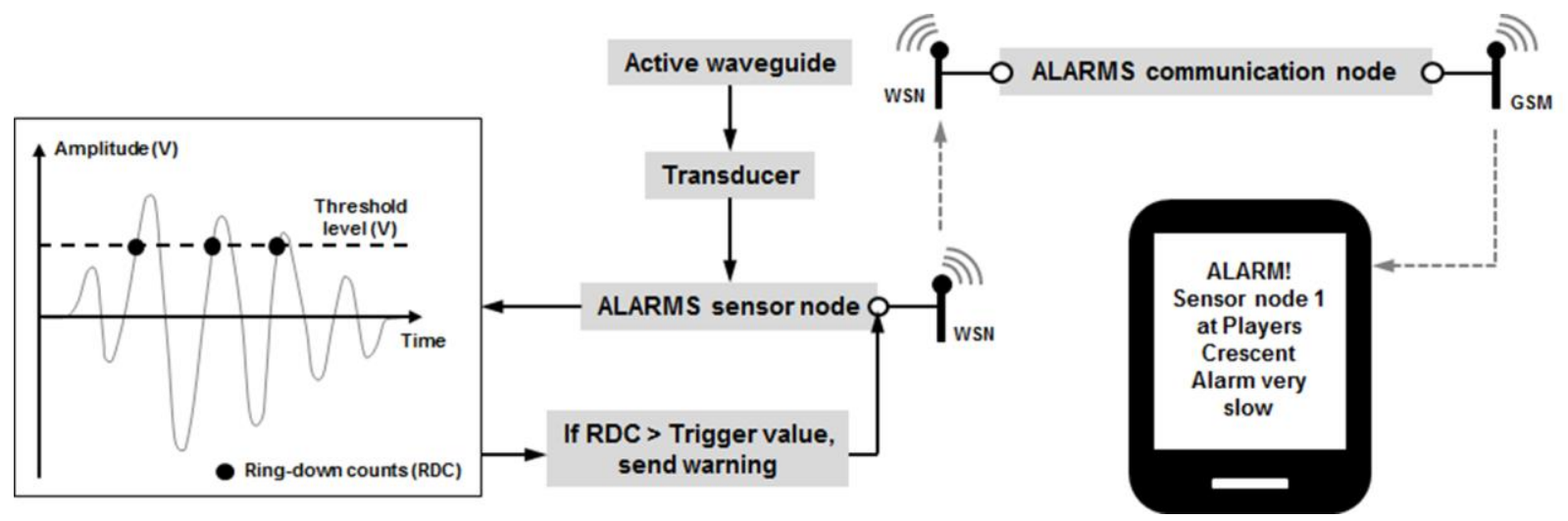

\section{Figure 3 Schematic of operation of the AE monitoring for soil slopes and communication system (after Smith et al. 2014c and Dixon et al. 2015). In rock slopes the active waveguide is replaced by a passive waveguide}

The application of the AE monitoring approach to rock slopes is different, and so is the interpretation of rock slope behaviour from measured AE. Monitoring equipment installed within rock slopes works in principle in the same way (Figure 3) although there is one fundamental difference: the metal waveguide is not surrounded by gravel backfill but grouted into the borehole for better coupling with the rock mass. This makes the waveguide primarily a passive system with detected $A E$ thus generated by stress release within the rock mass, which is transmitted to the waveguide rather than being generated by deformation of the grout backfill; although, it is possible that deformation of the grout infill can generate relatively low levels of AE. AE attenuation within rock is much lower than in soil (Koerner et al. 1981). Coupled with the high energy of $A E$ generated by fracture propagation mechanisms this means that high frequency stress waves are able to travel for relatively large distances within rock and hence they can be detected directly by $\mathrm{AE}$ monitoring equipment without the need for using waveguide generated $\mathrm{AE}$. Therefore, detected $\mathrm{AE}$ is not only generated from deformation of discontinuities crossed by the waveguide but also by deformation mechanisms within a volume or rock surrounding the waveguide that is monitored. The size of this volume depends on the specific material and structural characteristics that constitute the rock mass. This consideration becomes particularly important when there is not clear evidence of specific shear zones/surfaces to install the waveguide through. As some types of rock experience very small deformation prior to collapse, it could be very challenging to identify a distinct rupture surface.

This behaviour leads to the second fundamental difference from application of AE monitoring in soil materials, which concerns data interpretation. Increasing AE rates cannot be directly related to an increasing rate of deformation, they could rather be related to accelerating damage events at the micro-scale as forerunners of a macroscopic brittle failure. Evidence of accelerating patterns prior to collapse has been widely found at the laboratory sample scale (e.g. Lockner 1993) and precursory event trends are known also at the slope scale (e.g. Hardy 2003; Amitrano et al. 2005).

Identifying RDC rates that represent precursors of a big event is not straightforward, as there are a number of factors that contribute to stress release within the rock mass, such as variations in water pressure due to changes in the piezometric level or even earthquakes. Moreover, a possible source of noise is rainfall water infiltrating through rock discontinuities/porosity flowing onto the waveguide and generating high frequency waves. Interpretation of $A E$ generated by deforming rock slopes is not as well developed as for soils and research is ongoing to establish AE signatures that can be used to warn of instability.

\section{$3 \quad$ Field trial sites}

Details of the current soil and rock slope sites where AE monitoring is being trialled and compared to traditional monitoring techniques are presented in Table 1. The information includes site location, a summary of the setting, instrumentation installed, monitoring period and collaborating parties. The soil slope sites are primarily (i.e. excluding Scarborough) reactivated landslides that move following periods of 
triggering rainfall. These were selected as they provided certainty that slope deformations would occur in a reasonable time scale (i.e. most winters) thus providing the opportunity to assess performance of the $\mathrm{AE}$ monitoring technique and compare behaviour with direct deformation measurements. However, although the rock slopes being monitored have a history of instability, the monitoring is designed to detect first-time failure events. The complex potential failure mechanisms and uncertainty over the timing of failure events in different sections of the rock slope makes the location of waveguides, interpretation of measurements and likelihood of measuring a failure event considerably more complex than for soil slopes.

\section{Comparisons of measured AE and deformation behaviour}

\subsection{Soil slopes}

\section{Table 1 Summary of field trial sites}

\begin{tabular}{|c|c|c|c|c|c|}
\hline Site & Description & $\begin{array}{l}\text { Location and } \\
\text { setting }\end{array}$ & Instrumentation & $\begin{array}{l}\text { Monitoring } \\
\text { period }\end{array}$ & $\begin{array}{c}\text { Parties } \\
\text { involved }\end{array}$ \\
\hline \multicolumn{6}{|c|}{ Soil slopes } \\
\hline Hollin Hill & $\begin{array}{l}\text { Reactivated shallow } \\
\text { rotational and } \\
\text { translational slides. } \\
\text { Material: Whitby } \\
\text { Mudstone Formation. }\end{array}$ & $\begin{array}{l}\text { Farmers field near } \\
\text { Terrington, North } \\
\text { Yorkshire, UK. }\end{array}$ & $\begin{array}{c}\text { Inclo (3), SAA (2), } \\
\text { AEWG (3), GPS, } \\
\text { TM (2), Piezo (2), } \\
\text { RG. }\end{array}$ & $\begin{array}{l}\text { Winter } \\
\text { 2009/ } 2010 \\
\text { - present. }\end{array}$ & BGS \\
\hline Flat Cliffs & $\begin{array}{l}\text { Relatively deep-seated } \\
(14-\mathrm{m}) \text { reactivated } \\
\text { coastal slide. } \\
\text { Material: Glacial Till. }\end{array}$ & $\begin{array}{l}\text { Threatening 50+ } \\
\text { homes and } \\
\text { associated } \\
\text { infrastructure in } \\
\text { Filey, North } \\
\text { Yorkshire, UK. }\end{array}$ & $\begin{array}{l}\text { Inclo (1), } \\
\text { AEWG (1), } \\
\text { Piezo. }\end{array}$ & $\begin{array}{l}\text { September } \\
2011 \\
\text { - present. }\end{array}$ & $\begin{array}{l}\mathrm{CH} 2 \mathrm{M} \\
\mathrm{SBC}\end{array}$ \\
\hline $\begin{array}{l}\text { Scarbo- } \\
\text { rough }\end{array}$ & $\begin{array}{l}\text { Coastal slope with } \\
\text { potential for first-time } \\
\text { failure. } \\
\text { Material: Glacial Till. }\end{array}$ & $\begin{array}{l}\text { Threatening a road, } \\
\text { hotels and spa } \\
\text { complex in } \\
\text { Scarborough, North } \\
\text { Yorkshire, UK. }\end{array}$ & $\begin{array}{l}\text { Inclo (1), } \\
\text { AEWG (1), } \\
\text { Piezo. }\end{array}$ & $\begin{array}{l}\text { November } \\
2012 \\
\text { - present. }\end{array}$ & $\begin{array}{l}\mathrm{CH} 2 \mathrm{M} \\
\mathrm{SBC}\end{array}$ \\
\hline $\begin{array}{l}\text { Players } \\
\text { Crescent }\end{array}$ & $\begin{array}{l}\text { Reactivated slide in } \\
\text { cutting. } \\
\text { Material: Barton clay } \\
\text { formation. }\end{array}$ & $\begin{array}{c}\text { Threatening a } \\
\text { freight rail track in } \\
\text { Totten, } \\
\text { Southampton, UK. }\end{array}$ & $\begin{array}{c}\text { Inclo (1), SAA (1), } \\
\text { AEWG (2). }\end{array}$ & $\begin{array}{l}\text { February } \\
\text { 2011-April } \\
2014 .\end{array}$ & GO, NR \\
\hline Ruthlin & $\begin{array}{l}\text { Large rotational } \\
\text { reactivated slide. } \\
\text { Material: Alluvium } \\
\text { comprising clays, silts, } \\
\text { sands and gravels. }\end{array}$ & $\begin{array}{l}\text { Threatening roads } \\
\text { and houses near } \\
\text { Monmouth, UK, } \\
\text { requiring } \\
\text { remediation. }\end{array}$ & $\begin{array}{l}\text { Inclo (4), } \\
\text { Piezo (1), } \\
\text { AEWG (2). }\end{array}$ & $\begin{array}{l}\text { January } \\
2014 \\
\text { - present. }\end{array}$ & MCC, PB \\
\hline Dyffryn & $\begin{array}{l}\text { Recent slide failure. } \\
\text { Material: St Maughans } \\
\text { Formation; mudstone } \\
\text { and sandstone. }\end{array}$ & $\begin{array}{l}\text { Backscarp } \\
\text { intersected a road } \\
\text { near Monmouth, } \\
\text { UK, requiring } \\
\text { remediation. }\end{array}$ & $\begin{array}{l}\text { Inclo (3), } \\
\text { Piezo (1), } \\
\text { AEWG (1). }\end{array}$ & $\begin{array}{l}\text { January } \\
2014 \\
\text { - present. }\end{array}$ & MCC, PB \\
\hline Peace & Relatively deep-seated & Threatening a road & SAA (1), & July 2013 & AT, QU, \\
\hline
\end{tabular}




\begin{tabular}{|c|c|c|c|c|c|}
\hline Site & Description & $\begin{array}{l}\text { Location and } \\
\text { setting }\end{array}$ & Instrumentation & $\begin{array}{l}\text { Monitoring } \\
\text { period }\end{array}$ & $\begin{array}{c}\text { Parties } \\
\text { involved }\end{array}$ \\
\hline \multicolumn{6}{|c|}{ Soil slopes } \\
\hline River & $\begin{array}{l}\text { (-16 } \mathrm{m}) \text { slide } \\
\text { undergoing relatively } \\
\text { constant creep. } \\
\text { Material: Lacustrine } \\
\text { clay, till and sand. }\end{array}$ & $\begin{array}{l}\text { in Peace River, } \\
\text { Alberta, Canada. }\end{array}$ & AEWG (1). & - present. & TE \\
\hline $\begin{array}{l}\text { Passo della } \\
\text { Morte }\end{array}$ & $\begin{array}{l}\text { Relatively deep-seated } \\
(-25 \text { m) reactivated } \\
\text { slide. } \\
\text { Material: Clayey silt } \\
\text { with sand. }\end{array}$ & $\begin{array}{l}\text { Threatening a road } \\
\text { and tunnel in an } \\
\text { alpine valley, } \\
\text { eastern Italian Alps. }\end{array}$ & $\begin{array}{l}\text { In-place Inclo (2), } \\
\text { Piezo (2), RG, } \\
\text { AEWG (2). }\end{array}$ & $\begin{array}{l}\text { October } \\
2012 \\
\text { - present. }\end{array}$ & CNR-IRPI \\
\hline $\begin{array}{l}\text { Grossreif- } \\
\quad \text { ling }\end{array}$ & $\begin{array}{l}\text { Conglomerate (pebble } \\
\text { to boulder particle } \\
\text { size) slope } \\
\text { experiencing falls. }\end{array}$ & $\begin{array}{l}\text { Threatening a } \\
\text { freight rail track } \\
\text { near Grossreifling, } \\
\text { Austria. }\end{array}$ & $\begin{array}{c}\text { RG, VS, C (2), } \\
\text { AEWG (3). }\end{array}$ & $\begin{array}{l}\text { April } 2014 \\
\text { - present. }\end{array}$ & $\begin{array}{l}\text { OeBB, } \\
\text { INGLAS }\end{array}$ \\
\hline $\begin{array}{l}\text { Passo della } \\
\text { Morte }\end{array}$ & $\begin{array}{l}\text { Stratified limestone } \\
\left(70^{\circ} \text { dip) with marl }\right. \\
\text { infilling subject to } \\
\text { sliding between layers } \\
\text { and slides/falls along } \\
\text { other discontinuities. }\end{array}$ & $\begin{array}{l}\text { Threatening a road } \\
\text { tunnel in an alpine } \\
\text { valley, eastern } \\
\text { Italian Alps. Valley } \\
\text { damming is also a } \\
\text { potential threat. }\end{array}$ & $\begin{array}{c}\text { Inclo (1), } \\
\text { Piezo (1), TDR (5), } \\
\text { Ext (3), CM (3), } \\
\text { Seis (1), Acc (4), } \\
\text { TS, RG, } \\
\text { AEWG (3). }\end{array}$ & $\begin{array}{l}\text { December } \\
2010 \\
\text { - present. }\end{array}$ & CNR-IRPI \\
\hline $\begin{array}{l}\text { Instrumentation: } \\
\text { Extensometer (Ex } \\
\text { sensors (VS), Cam } \\
\text { Parties: Alberta T } \\
\text { Observations Ltd } \\
\text { Protection (CNR- } \\
\text { Scarborough Borc }\end{array}$ & $\begin{array}{l}\text { Inclinometer (Inclo), ShapeAccelAr } \\
\text { ), Crackmeter (CM), Seismometer } \\
\text { ra (C), Tilt meter (TM), GPS marke } \\
\text { ansportation (AT), Austrian Feder } \\
\text { GO), Inglas GmbH - Impact Sentine } \\
\text { RPI), Monmouthshire County Cour } \\
\text { ugh Council (SBC), Thurber Engine }\end{array}$ & $\begin{array}{l}\text { ay (SAA), Time-domain reflect } \\
\text { Seis), Accelerometer (Acc), Te } \\
\text { r monitoring (GPS). } \\
\text { I Railways (OeBB), British Geol } \\
\text { I (INGLAS), Italian National Res } \\
\text { cil (MCC), Network Rail (NR), P } \\
\text { ring (TE). }\end{array}$ & $\begin{array}{l}\text { ometry (TDR), Waveguide (A } \\
\text { nperature sensor (TS), Rain } \\
\text { ggical Survey (BGS), CH2M I } \\
\text { earch Council - Research Ins } \\
\text { arsons Brinckerhoff (PB), Qu }\end{array}$ & $\begin{array}{l}\text { EWG), Piezometer } \\
\text { auge (RG), Catch-f } \\
\text { ill (CH2M), Geotech } \\
\text { itute for Geo-Hydr } \\
\text { een's University, Ki }\end{array}$ & $\begin{array}{l}\text { Piezo), } \\
\text { nce vibration } \\
\text { nical } \\
\text { logical } \\
\text { gston (QU), }\end{array}$ \\
\hline
\end{tabular}

\subsubsection{Hollin Hill field trial}

\subsubsection{Comparisons with conventional inclinometer measurements for a single deformation event}

Figure 4 shows the typical AE response to a reactivated slope movement event at Hollin Hill. Note that the inclinometer measurements (produced from manual surveys of the casing) are separated by an interval of seven days and therefore have low temporal resolution. During the reactivation event both the velocity of the sliding mass and the AE rates generated increase exponentially until they reach a peak, at which point they subsequently decay exponentially as pore-water pressures dissipate, shear resistance is mobilised within the slide mass and through remoulding of the landslide toe. The shape of this curve is analogous to the conceptual velocity-time relationship for reactivation events described by Leroueil (2001). This produces the ' $S$ '-shaped displacement-time curve that was derived from the AE rate data (through determination of the rate of change with respect to time and equating the area under the curve to the magnitude of displacement measured by the inclinometer; a method developed in Dixon et al. 2014) and provides increased temporal resolution for the deformation event. 


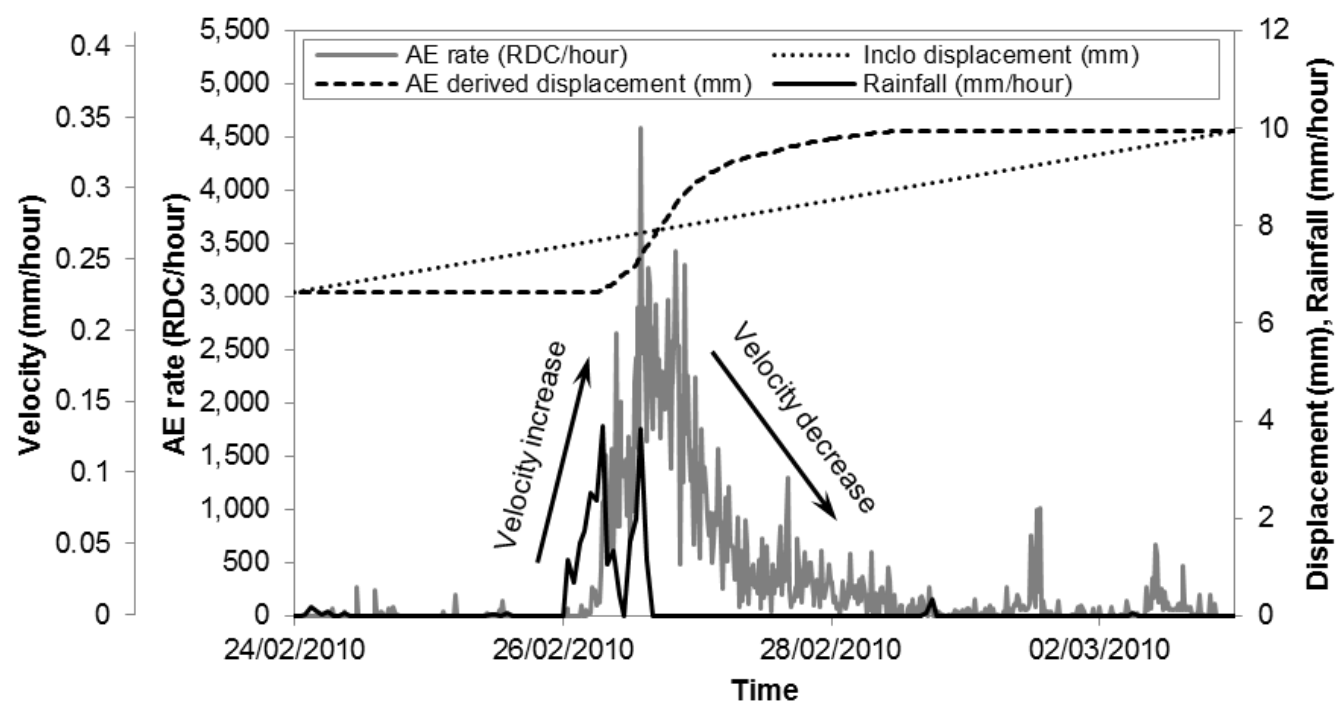

Figure 4 AE rate-, AE derived velocity-, inclinometer measured displacement-, AE derived displacement- and rainfall-time series for a reactivated slope deformation event at Hollin Hill after Dixon et al. (2014)

\subsubsection{Comparisons with continuous SAA measurements for multiple deformation events}

SAAs installed at Hollin Hill have allowed the comparison of continuous AE with continuous subsurface deformation measurements. A series of reactivated slope movements (i.e. small magnitude displacements with low velocities as the shear surface is already at or near residual strength (Hutchinson 1988; Leroueil 2001) occurred in response to periods of rainfall that produced transient elevations in porewater pressure along the shallow shear surface in January 2014 (Figure 5). Note that the smoothed curves were calculated using 10-hour moving average values. These comparisons confirm that: AE rates generated by the system are directly proportional to the rate of deformation; AE monitoring of active waveguides can provide continuous information on slope displacements and displacement rates; and the technique is sensitive to small displacements, displacement rates (i.e. less than $1 \mathrm{~mm}$ per hour) and changes in displacement rates (i.e. accelerations and decelerations). 
(a)

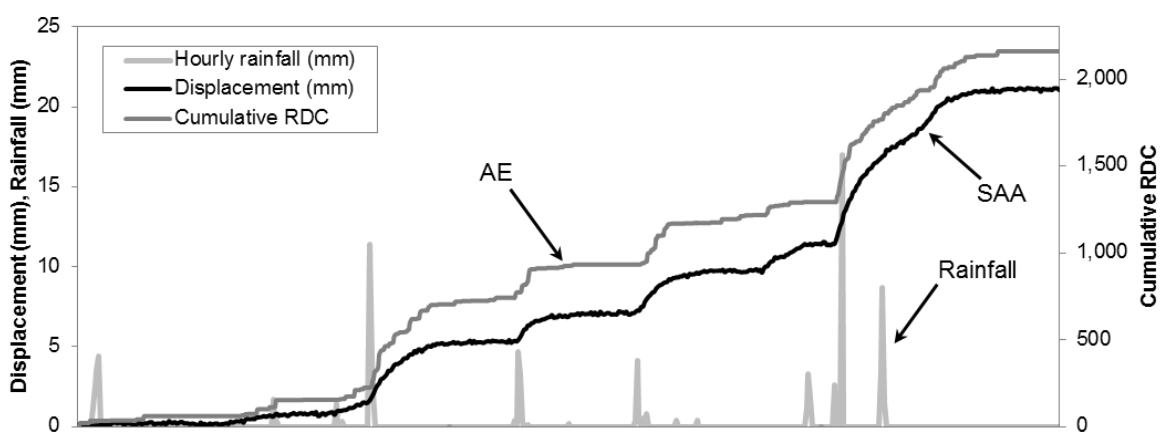

(b)

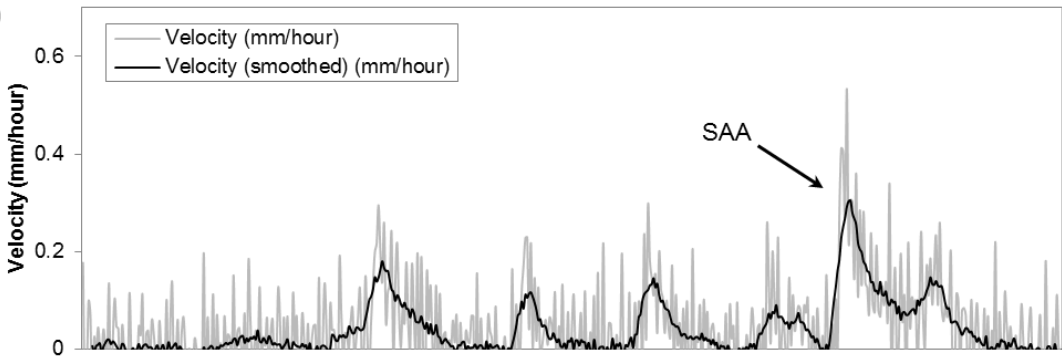

(c)

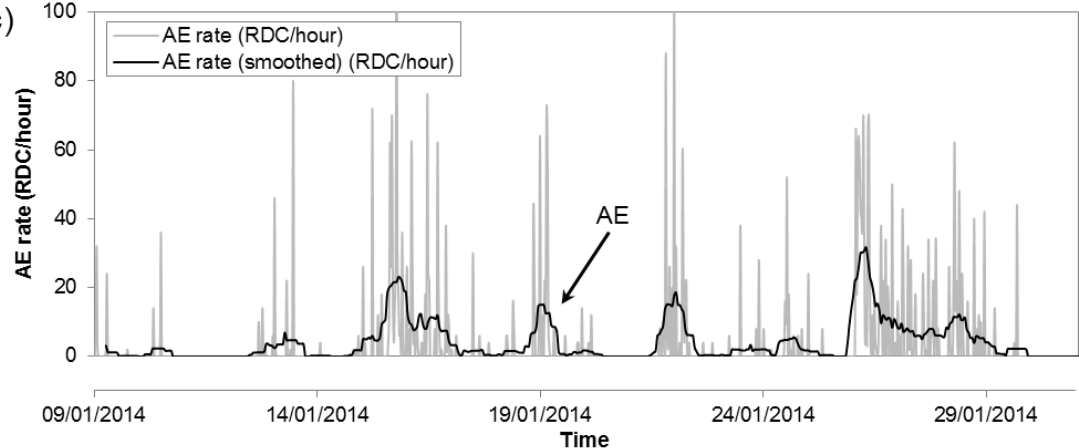

Figure 5 Time series for reactivated movements at Hollin Hill: (a) Rainfall, cumulative AE and cumulative SAA displacement; (b) SAA velocity; and (c) AE rate (after Smith et al. 2014a)

\subsubsection{Players Crescent field trial}

\subsubsection{Comparisons with continuous SAA measurements for a 'very slow' deformation event}

Figure 6(a) shows cumulative RDC, deformation and hourly rainfall with time for a period of slope movement that occurred between 19 April and 5 May 2012 at Players Crescent. The continuous deformation information was recorded by an SAA installed down-slope (i.e. near the toe, adjacent to an $A E$ monitoring system). Figure $6(\mathrm{~b})$ shows the $A E$ rate (RDC/hour) time series superimposed on top of the same deformation event. Approximately $1.2 \mathrm{~mm}$ of shear surface deformation occurred during this 16-day period. The gradient of the SAA deformation-time series during the event was relatively constant and therefore the velocity of movement was relatively constant. The velocity can therefore be determined using the displacement/time relation and this generates values of $0.075 \mathrm{~mm} /$ day or $0.003 \mathrm{~mm} / \mathrm{hour}$; these rates of movement would be classified as 'very slow' according to Cruden and Varnes (1996). The active waveguide and $A E$ sensor node also detected this small, low velocity slope movement event. Of particular interest is the dramatic continual increase in $A E$ rates as slope movement initiates and this continues throughout the 'very slow' deformation event.

The AE system produced continuous information with high temporal resolution, which demonstrates the potential of the system to provide alternative deformation rate information to detect and provide an early warning of slope movements. The ability of the AE system to detect such small low velocity slope movements highlights its potential for use as an early warning system. Unfortunately, the AE data ended on 
3 May 2012 due to reaching storage capacity on the datalogger, so the final two days of the deformation event were not monitored. However, based on monitoring trends from similar events at other sites, it is expected that the $A E$ rates generated by the active waveguide would have reduced as the rate of slope movement reduced. Additionally, the gradient of the cumulative RDC curve would gradually decrease and become horizontal as deformation ceased, and the column of gravel backfill would approach equilibrium (as in the slope movement events shown in Figure 5).

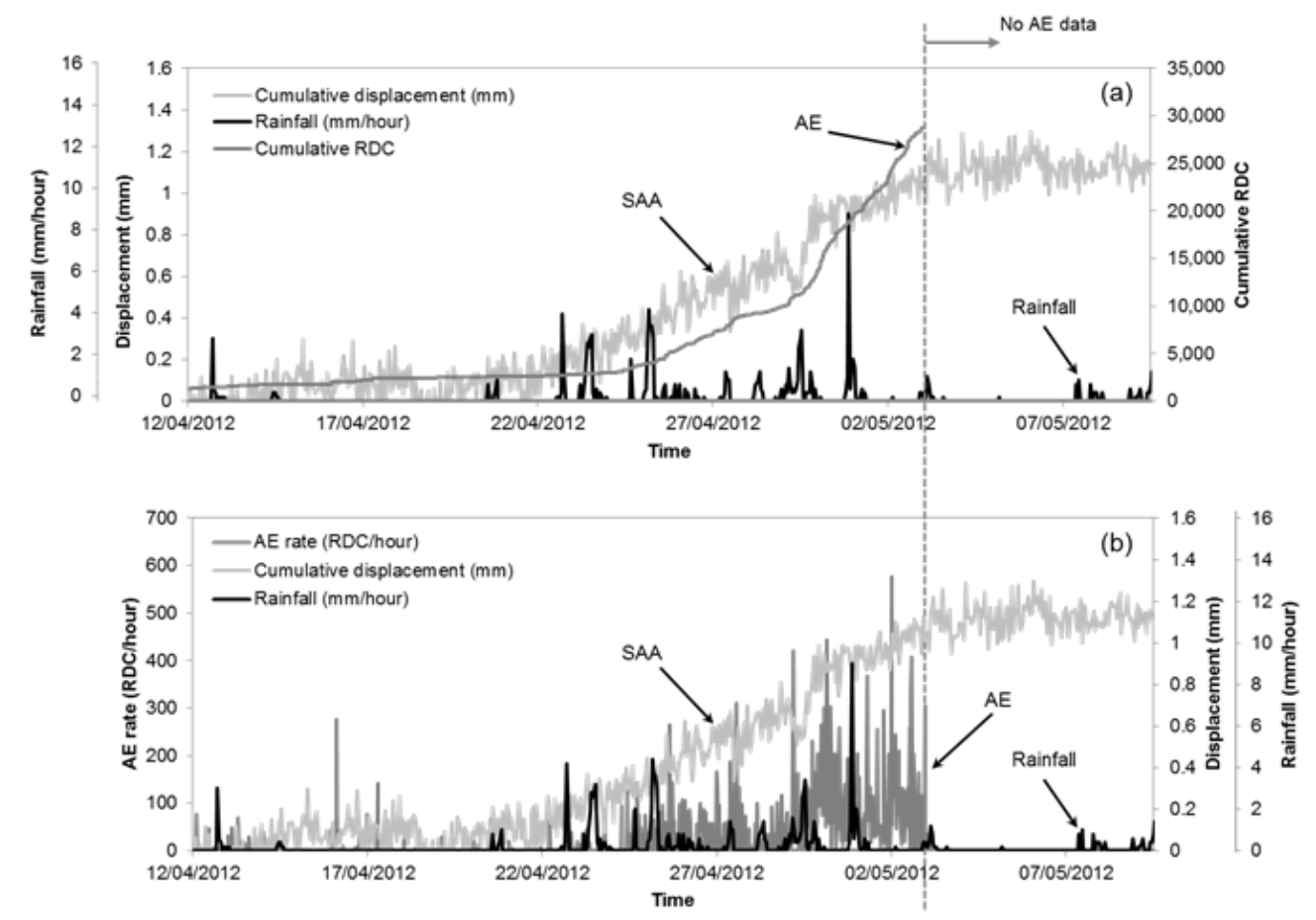

Figure 6 (a) Cumulative RDC, displacement and hourly rainfall versus time for a small magnitude low velocity reactivated deformation event, and (b) AE rate (RDC/hour), displacement and hourly rainfall versus time (data from the SAA and AEWG near the toe of the slope) (after Dixon et al. 2015)

\subsubsection{Comparisons with conventional inclinometer measurements from multiple AE installations on a single slope}

Pre-defined trigger levels were set on the sensors at Players Crescent related to displacement rates. If the measured RDC in any given monitoring period exceeded one of the trigger levels, a SMS message was generated. The communication system sent a SMS alarm status on 24 November 2012 at $0700 \mathrm{~h}$, which stated that AEWG1 (near the toe) had detected 'very slow' movement as the AE rate exceeded 2,000 RDC/hour (Figure 7).

Another SMS was sent on 25 November 2012 at 0630 h, which stated that AEWG2 (near the head) had also detected 'very slow' movement (both of these were received by the author's mobile phones, one of which was in Peru at the time). Only one text message was generated at each of the two instrument locations during this period of movement because the AE rates subsequently decreased beneath the lowest trigger threshold in the successive measurement intervals. These warnings were generated by the peaks in the bell-shaped AE rate-time curves shown in Figure 7, which are characteristic of deformation events.

Figure 7 shows the AE rate, inclinometer displacement and hourly rainfall versus time series for the period in which the deformation events and alarm SMS messages were triggered. The 11.5 hours which separated the warning messages indicated that movement had been detected in the lower part of the slope prior to being detected in the upper section of the slope. Subsequent interrogation of the data shown in Figure 7 confirmed that the toe of the slope indeed moved before the head (i.e. AEWG1 generated a bell-shaped AE rate curve prior to AEWG2). 


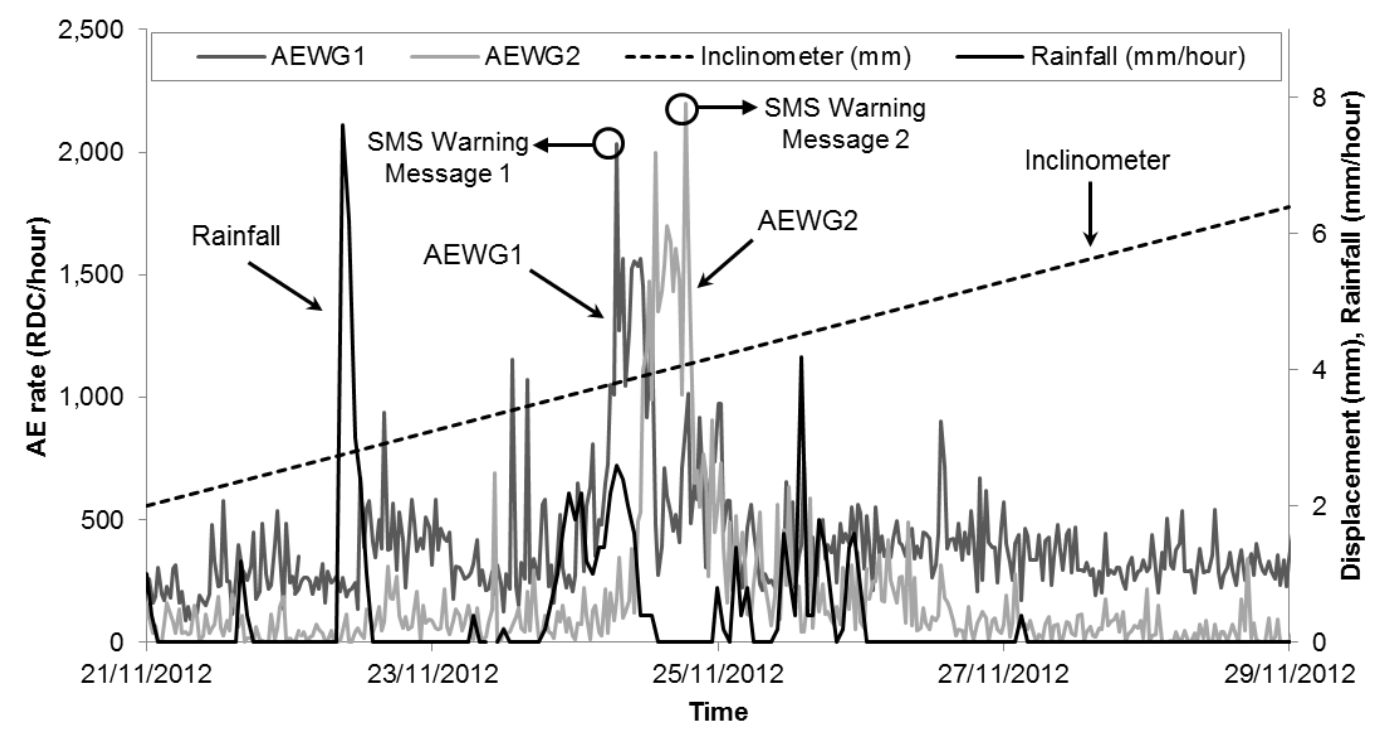

Figure $7 \mathrm{AE}$ rate (RDC/hour), inclinometer measured displacement and hourly rainfall versus time for a period of slope movement in response to intensive rainfall (data from AEWG1 (near the toe), AEWG2 (near the head) and the inclinometer), the timing of the SMS warning messages are also shown (after Dixon et al. 2015)

An extended period of intense rainfall occurred at the location of the site prior to, and during, the deformation events. This rainfall provided for a build-up of pore-water pressures in the vicinity of the shear surface sufficient to reduce the effective stress and induce movement. This was followed by a deceleration of movements as pore-water pressures dissipated and due to mobilisation of shear resistance internally in the slide mass and through remoulding at the landslide toe. Unfortunately, the SAA datalogger reached storage capacity prior to this period and therefore continuous deformation data was not available for comparison. However, interpretation of inclinometer measurements confirmed that deformation had occurred during this period but the rate of movements with time is unknown. This episode has demonstrated the ability of the Slope ALARMS AE monitoring system to detect and communicate warnings of slope movements.

\subsection{Rock slope: Passo della Morte}

Application of the AE monitoring approach to rock slopes using grouted waveguides is recent (Dixon et al. 2012b). The Passo della Morte trial site in the Italian Alps (Figure 8) was set up four years ago and data have been collected continuously. This long data set has been cleaned to remove environmentally generated $A E$ (e.g. from sensor maintenance and construction activity) and systematically analysis has commenced. A preliminary overview of the most recurring types of $A E$ events is presented in the following sections. It should be noted that there is still not enough experience to determine which processes are generating the measured $A E$ behaviour. A key part of the work to identify the link between rock deformation mechanisms and generated $A E$ is on-going evaluation of data from a wide range of classical geotechnical monitoring instruments, such as extensometers, crackmeters, TDR cables and an inclinometer. Three AE waveguides are located through the steeply dipping limestone layers that form the rock mass being monitored due to concerns over slope stability. They were all installed from a road tunnel located in the limestone with only shallow (tens of metres) of cover. AEWG1 is 50 metres in length and penetrates into the rock mass away from the slope and AEWG2 (30 metres in length) and AEWG3 (10 metres in length) penetrate the limestone layers between the tunnel and the slope surface. The AE sensors are located in the tunnel within 50 metres of each other. As for the soil monitoring system, the sensors record RDC for set monitoring periods, typically set at 15 minutes. The RDC recorded are a function of the sensitivity of the sensor, the magnitude of $A E$ events generated by deformation of the rock mass and the attenuation that occurs as the $A E$ signals propagate through the rock to the waveguide and along the waveguide to the sensor. Therefore, relative 
magnitude of $A E$ rates, trends of $A E$ behaviour with time and comparisons between waveguides are being used to provide information on deformation mechanisms rather than absolute values.

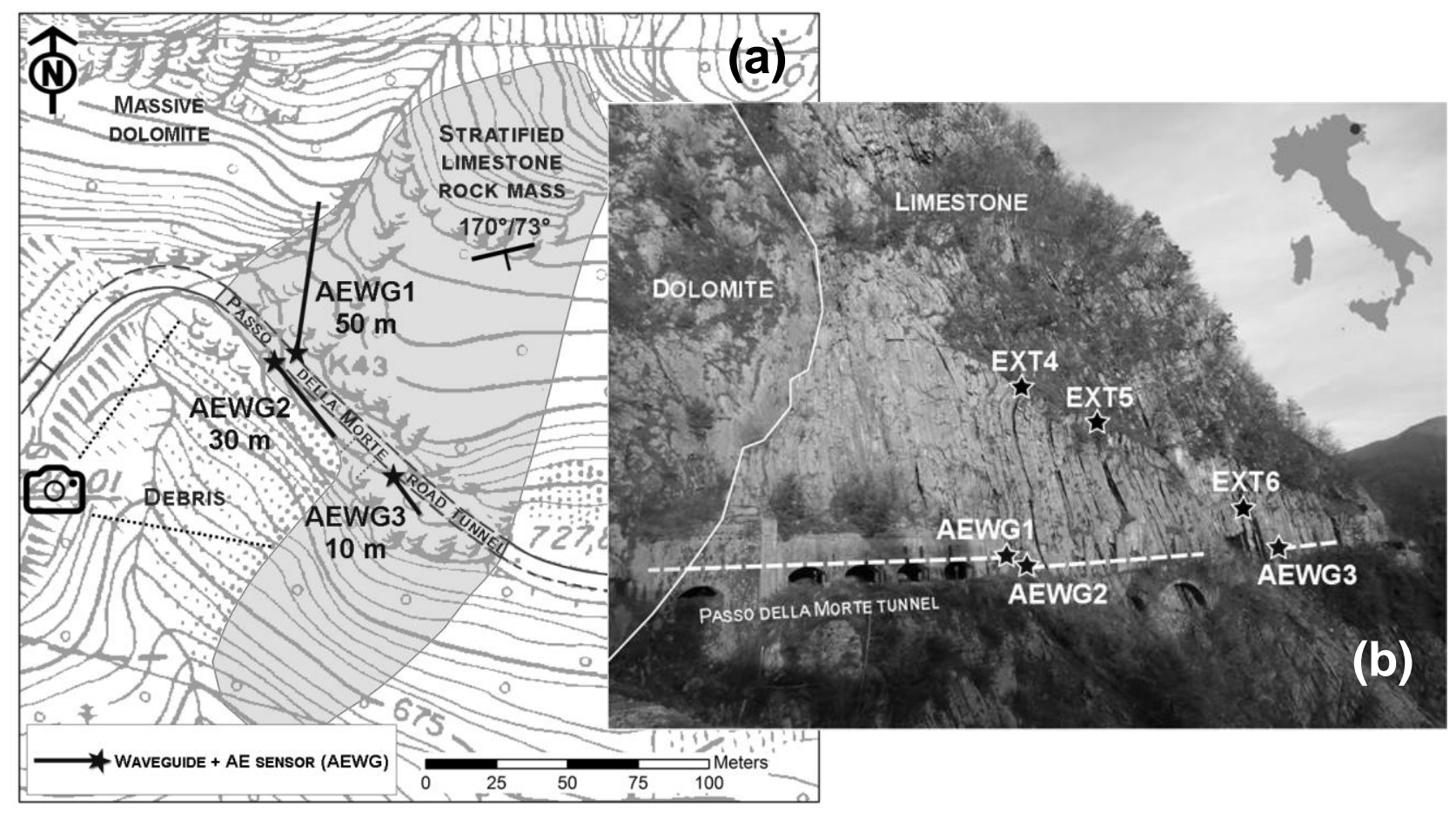

Figure 8 Passo della Morte (Forni di Sotto, Italy) trial site: (a) schematic of the unstable limestone rock mass and position of the three waveguides (AEWG1, AEWG2, AEWG3); and (b) photo of the west rock mass face with projection of the waveguides position and location of crackmeters (EXT4, EXT5, EXT6)

\subsubsection{AE trends}

\subsubsection{Low $A E$ rate events ( $<1,000$ RDC/hour)}

Low $A E$ rate events are rather common throughout the data series. As can be seen in Figure 9, they occur both during rainfall events and during dry periods and their duration is from hours to a few days, with occasional spikes of $A E$ that are several times higher than the average. These events are often recorded by all the three sensors (AEWG1, AEWG2 and AEWG3). 


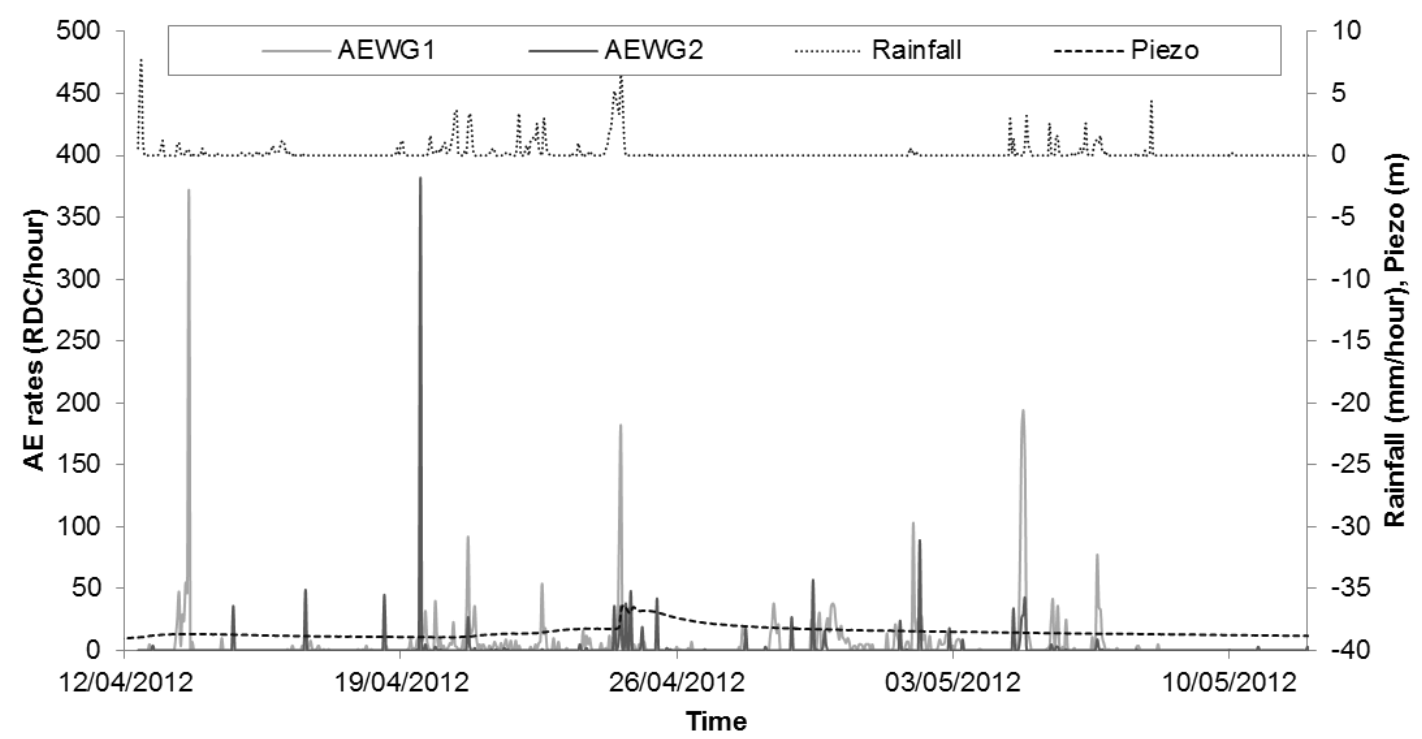

Figure 9 AE rate (RDC/hour), rainfall ( $\mathrm{mm} / \mathrm{hour}$ ) and piezometric level $(\mathrm{m})$ versus time for low AE rate events ( $<1,000 \mathrm{RDC} /$ hour). AEWG3 was not installed in early 2012

\subsubsection{Medium AE rate events (1,000-10,000 RDC/hour)}

Medium AE rate events usually last for a few days and are recorded in particular from one sensor while the other two are silent or show lower activity levels. As in the example in Figure 10, they do not seem to be associated with particular rainfall events and the piezometric level does not change. These types of events can show a sharp increase at the beginning, as shown in Figure 10, or they can gently rise to a peak AE rate, but in both cases, the rates usually decrease gradually.

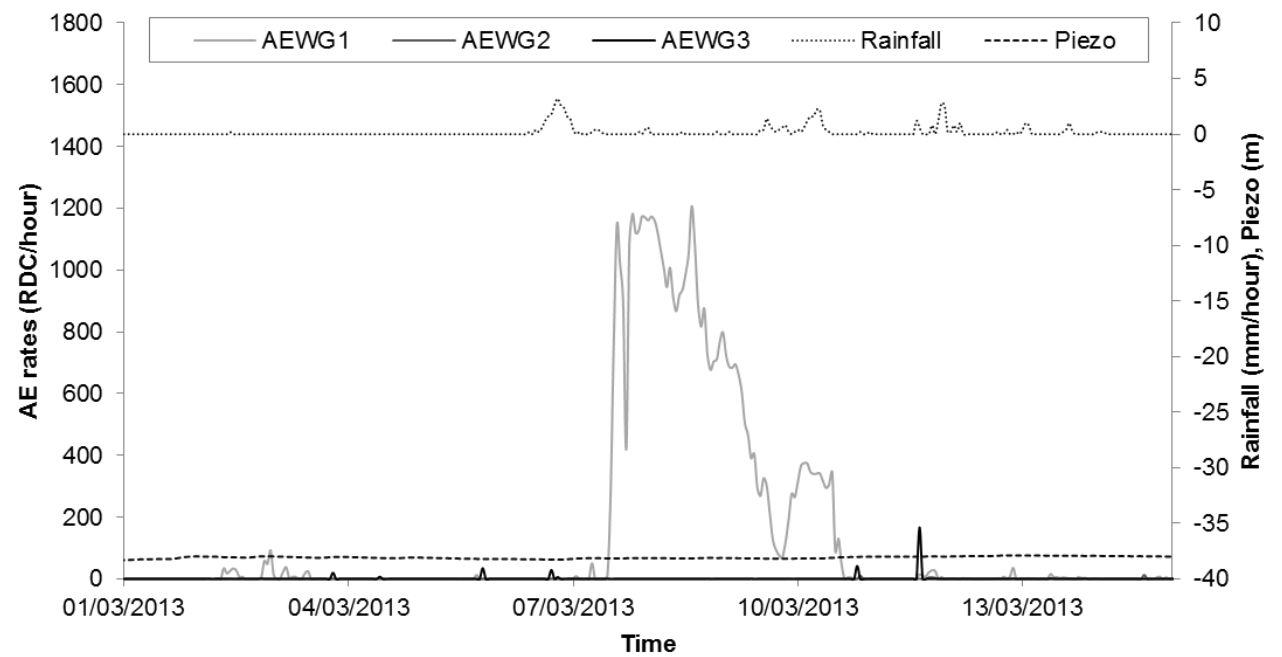

Figure $10 \quad A E$ rate $(\mathrm{RDC} / \mathrm{h})$, rainfall $(\mathrm{mm} / \mathrm{hour})$ and piezometric level $(\mathrm{m})$ versus time for medium AE rate events $(1,000-10,000 \mathrm{RDC} / \mathrm{h})$

\subsubsection{High AE rate events (10,000-100,000 RDC/hour)}

High AE rate events are usually sharp singular spikes, which last for one monitoring period (i.e. 1 hour in the example), and certainly for not more than two or three consecutive monitoring periods. Spikes in AE can be grouped in clusters within a few days (Figure 11) or be isolated. Rainfall does not seem to be critical for their occurrence.

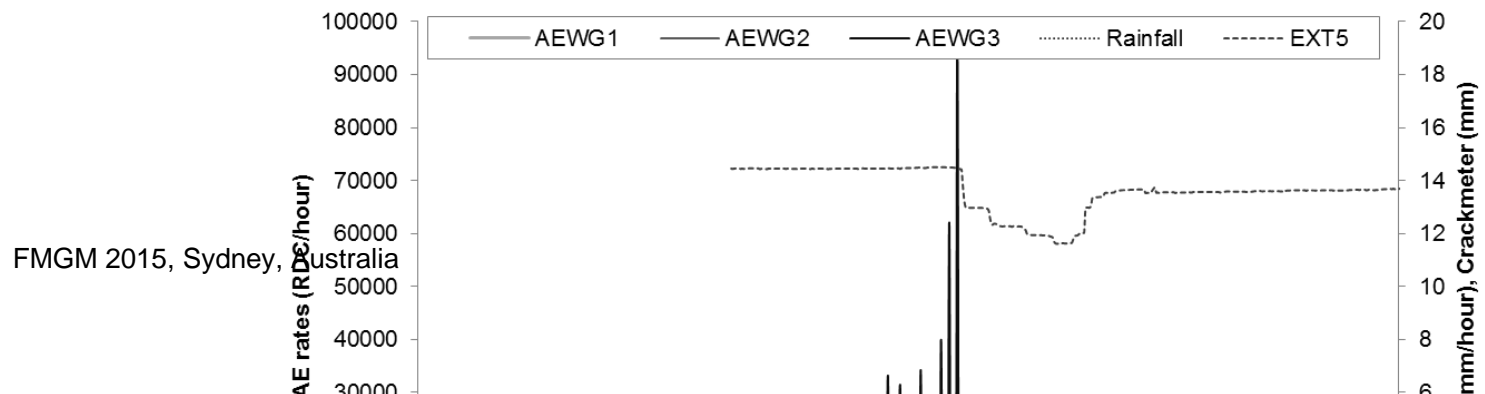


Figure 11 AE rate $(\mathrm{RDC} / \mathrm{h})$, rainfall ( $\mathrm{mm} / \mathrm{hour})$, piezometric level $(\mathrm{m})$ and crackmeter displacement $(\mathrm{mm})$ versus time for high AE rate events $(10,000-100,000 \mathrm{RDC} / \mathrm{h})$

These types of events are recorded simultaneously by all three sensors, although AEWG3 consistently records RDC rates higher by about one order of magnitude compared with AEWG1 and AEWG2. It is interesting to observe that the first part of the cluster in Figure 11 precedes the displacement recorded by a crackmeter (EXT5), which monitors one of the key discontinuities where it daylights on the slope, and the cluster ends when the crackmeter stabilises.

\subsubsection{AE events due to changes in water pressure}

Figure 12 shows a series of AE events that occurred in November 2014 and which lasted for several days. These events can be attributed to changes in water pressure within the rock mass due to variations in the piezometric level. It can be observed that there is a delay of some hours between rainfall events and the rise in the water level, but AE are recorded by waveguide AEWG1 simultaneously with changes in the water level. $A E$ rates tend to accelerate when the water table rises and to decrease, more or less sharply, when it drops. Hence, the AE trend follows the stress changes within the rock structure.

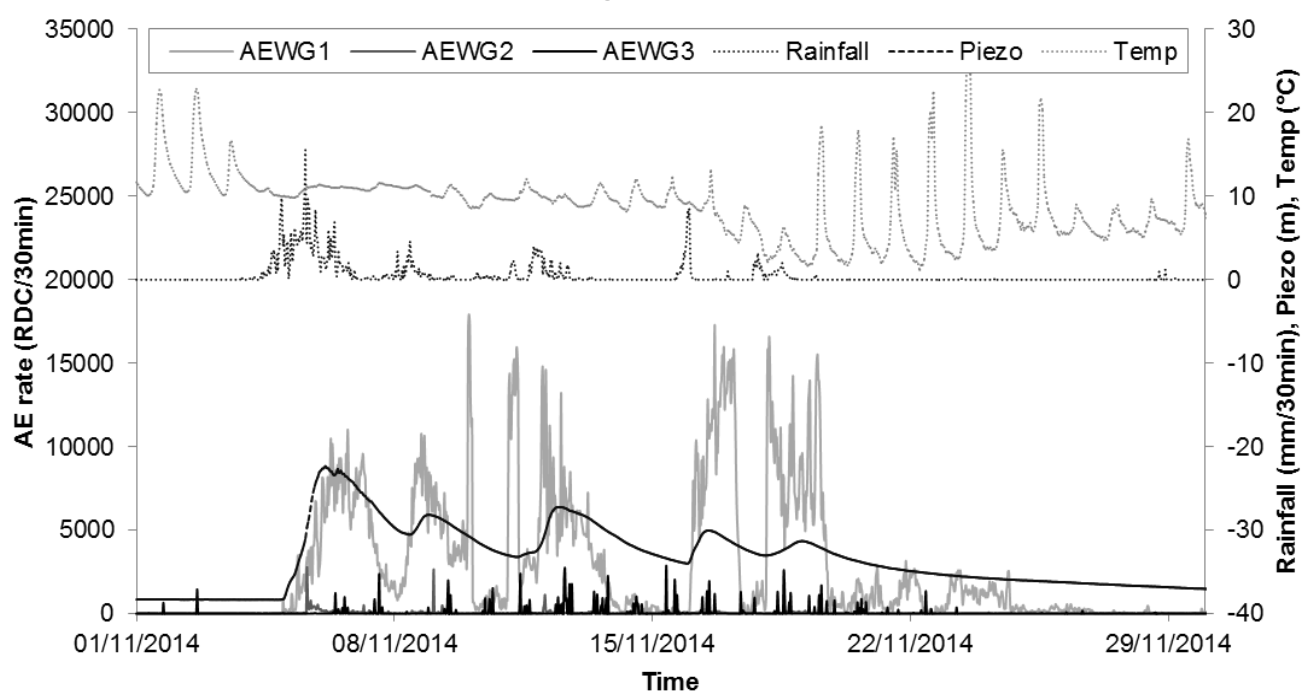

Figure $12 \quad A E$ rate (RDC/30 $\mathrm{min})$, piezometric level $(\mathrm{m})$, rainfall $(\mathrm{mm} / 30 \mathrm{~min})$ and temperature versus time showing $A E$ rate trends due to changes in piezometric level. Data are plotted for 30 -minute periods

The AE rate trends presented are clearly in response to changes in stress and resulting deformations in the rock mass. Continuing measurements and analysis at Passo della Morte and the Grossreifling rock slope in Austria, in conjunction with laboratory and field testing programmes, are being used to derive relationships between $A E$ rates and deformations with the aim of developing criteria for identifying the onset of catastrophic collapse and hence to provide an early warning. 


\section{$5 \quad$ Summary - an early warning acoustic emission monitoring system}

Ideally, an early warning system for the detection of slope instability should provide sufficient warning to enable relevant action to be taken (e.g. implement emergency plan); produce no false alarms, as this undermines confidence in the system; provide information on the rates and magnitude of movement to allow the likelihood and significance of an event to be assessed; and modes of failure should be identifiable, as this also allows an assessment of the significance of an event to be conducted.

For soil slopes, the field evidence from multiple long-term trials, supported by controlled laboratory studies, prove conclusively that $A E$ rates measured using an active waveguide system are proportional to slope displacement rates. AE rates can show when the slope is stable, accelerating or decelerating. Therefore, when used with user defined thresholds AE monitoring can provide a warning of instability. In addition, the $A E$ monitoring technique has been shown sensitive to small magnitudes of movement and very slow slope displacement rates, which means that it can provide early information on the occurrence of slope movements and changes in the rates of these movements. This information is automatically communicated in near real-time to nominated parties so that appropriate actions can be taken. Monitoring of AE has been in progress at example sites (e.g. Hollin Hill) for over four years with very few false alarm events, giving confidence in the robustness of the approach. The one limitation of the existing system is that it cannot provide information on the depth to the shear zone. It is concluded that the Slope ALARMS measurement approach can provide continuous and near real-time information on soil slope displacement rates and can be used to provide an early warning of failure.

$A E$ monitoring in rock slopes employing grouted waveguides is showing potential to provide information on rock mass deformation mechanisms. Field measurements of $A E$ rate trends may be useful to identify different source mechanisms and the magnitude and distribution with time of events is indicative of relative stability. However, further work is required to associate AE behaviour with specific rock mass deformation mechanisms and also to establish criteria for setting thresholds that can be used to trigger early warnings of failure.

\section{Acknowledgement}

The Engineering and Physical Sciences Research Council (EPSRC), UK, funded much of the Slope ALARMS research and development. Thanks are also due to CNR IRPI for funding the instrumentation and monitoring at Passo della Morte. Meldrum publishes with the permission of the Executive Director of the British Geological Survey (NERC).

\section{References}

Amitrano, D, Grasso, JR \& Senfaute, G 2005, 'Seismic precursory patterns before a cliff collapse and critical point phenomena', Geophysical Research Letters, vol. 32, no. 8, pp. 1-5.

Cruden, DM \& Varnes, DJ 1996, 'Landslide types and processes', in KA Turner \& RL Schuster (eds), Landslides-Investigation and mitigation: Transportation Research Board Special report no. 247, National Research Council, National Academy Press, Washington, pp. 36-75.

Dixon, N \& Spriggs, M 2007, 'Quantification of slope displacement rates using acoustic emission monitoring', Canadian Geotechnical Journal, vol. 44, no. 6, pp. 966-976.

Dixon, N, Hill, R \& Kavanagh, J 2003, 'Acoustic emission monitoring of slope instability: development of an active wave guide system', Institution of Civil Engineers Geotechnical Engineering Journal, vol. 156, no. 2, pp. 83-95.

Dixon, N, Smith, A, Spriggs, MP, Ridley, A, Meldrum, P \& Haslam, E 2015, 'Stability monitoring of a rail slope using acoustic emission', Proceedings of the Institution of Civil Engineers: Geotechnical Engineering (accepted for publication).

Dixon, N, Spriggs, MP, Marcato, G \& Pasuto, A 2012b, 'Landslide hazard evaluation by means of several monitoring techniques, including an acoustic emission sensor', in EB Ebernhardt (ed.), Landslides and Engineered Slopes: Protecting Society Through Improved Understanding: Proceedings of the 11th International and 2nd North American Symposium on Landslides and Engineered Slopes, CRC Press, Boca Raton, pp. 1405-1411.

Dixon, N, Spriggs, MP, Meldrum, P \& Haslam, E 2012a, 'Field trial of an acoustic emission early warning system for slope instability', in EB Ebernhardt (ed.), Landslides and Engineered Slopes: Protecting Society Through Improved Understanding: Proceedings 
of the 11th International and 2nd North American Symposium on Landslides and Engineered Slopes, CRC Press, Boca Raton, FL, pp. 1399-1404.

Dixon, N, Spriggs, MP, Smith, A, Meldrum, P \& Haslam, E 2014, 'Quantification of reactivated landslide behaviour using acoustic emission monitoring', Landslides, vol. 13, no. 3. pp. 549-560.

Glendinning, S, Hall, J \& Manning, L 2009, 'Asset-management strategies for infrastructure embankments', Proceedings of the Institution of Civil Engineers: Engineering Sustainability, vol. 162, no. 2, pp. 111-120.

Hardy, HR 2003, Acoustic Emission/Microseismic Activity Volume 1: Principles, Techniques and Geotechnical Applications, CRC Press, Boca Raton, FL.

Hutchinson, JN 1988, 'General report: Morphological and geotechnical parameters of landslides in relation to geology and hydrogeology', in C Bonnard (ed.), Proceedings of the 5th International Symposium on Landslides, Balkema, Rotterdam, pp. 3-35.

Koerner, RM, McCabe, WM \& Lord, AE 1981, 'Overview of acoustic emission monitoring of rock structures', Rock Mechanics, vol. 14, no. 1, pp. 27-35.

Leroueil, S 2001, 'Natural slopes and cuts: movement and failure mechanisms', Geotechnique, vol. 51, no. 3, pp. 197-243.

Lockner, D 1993, ' The role of acoustic emission in the study of rock fracture', International Journal of Rock Mechanics and Mining Sciences, vol. 30, no. 7, pp. 883-899.

Petley, DN 2012, 'Global patterns of loss of life from landslides', Geology, vol. 40, no. 10, pp. 927-930.

Smith, A \& Dixon, N 2014, 'Quantification of landslide velocity from active waveguide-generated acoustic emission', Canadian Geotechnical Journal, vol. 52, no. 4, pp. 413-425.

Smith, A, Dixon, N, Berg, N, Take, A \& Proudfoot, D 2014b, 'Listening for landslides: method, measurements and the peace river case study', Proceedings of the 6th Canadian GeoHazards Conference, Canadian Geotechnical Society, Richmond, British Columbia, $10 \mathrm{p}$.

Smith, A, Dixon, N, Meldrum, P \& Haslam, E 2014c, 'Inclinometer casings retrofitted with acoustic real-time monitoring systems', Ground Engineering Magazine, October 2014 issue.

Smith, A, Dixon, N, Meldrum, P, Haslam, E \& Chambers, J 2014a, 'Acoustic emission monitoring of a soil slope: comparisons with continuous deformation measurements', Geotechnique Letters, vol. 4, no. 4, pp. 255-261. 